\title{
Que língua os materiais didáticos de português como língua estrangeira ensinam?
}

\section{What language do teaching materials for Portuguese as a foreign language teach?}

\author{
Ana Paula Huback* \\ *Columbia University, New York, New York/Estados Unidos da América \\ aphuback@gmail.com \\ https://orcid.org/0000-0002-4467-2031
}

\begin{abstract}
Resumo: Neste artigo, analisa-se que modelo de língua, dentro do continuum entre fala e escrita, é apresentado nos livros didáticos de português como língua estrangeira (PLE). Selecionamos cinco livros didáticos e observamos como eles apresentam os seguintes temas: pronomes oblíquos, pronomes demonstrativos, pronomes pessoais retos, pronúncia do verbo estar e preposição para. Observou-se que a maioria dos materiais adota a norma padrão como parâmetro para os conteúdos. Variantes mais informais da língua são negligenciadas, mesmo quando os exercícios simulam conversas informais. A situação de comunicação em que os falantes se encontram também não é considerada. Questiona-se se a língua padrão é o parâmetro de ensino mais adequado para promover o letramento de alunos de PLE e sua inserção em um ambiente informal no Brasil. Apresentam-se, também, sugestões de tópicos de língua falada que podem ser incorporados ao ensino de PLE.
\end{abstract}

Palavras-chave: português como língua estrangeira; variação linguística; livros didáticos de português como língua estrangeira; norma padrão.

\begin{abstract}
This article analyzes how textbooks of Portuguese as a second language dThis article analyzes how textbooks of Portuguese as a second language deal with the spectrum of language variation imposed by Brazilian Portuguese. This study was conducted with five textbooks, comparing five grammar topics across them: object pronouns, demonstrative pronouns, subject pronouns, pronunciation of the verb estar ('to be'), and the preposition para ('to', 'for'). The results indicate that most materials present a highly standard variation of Portuguese, with colloquial variants being mostly neglected even in exercises mimicking informal dialogues. The materials also ignore the communicative situation in which speakers were inserted. In this scenario, the article questions whether an approach to Portuguese language based on the standard variation would be the best teaching strategy for promoting literacy and the socialization of students in Brazil. We also suggest some topics related to informal Portuguese that could be incorporated in language classes.
\end{abstract}

Keywords: Portuguese as a foreign language; language variation; textbooks of Portuguese as a second language; standard language. 


\section{Introdução}

Este artigo analisa cinco livros didáticos de português como língua estrangeira (PLE) com o objetivo de investigar que modalidade de língua esses materiais usam em sua pedagogia de ensino. O critério de escolha foi temporal: usamos livros cuja última edição tem menos de 10 anos.1 Com esse filtro de tempo, selecionamos livros que são relativamente atuais e já tiveram chances de se adaptar a estudos mais recentes da língua falada e sua aplicação ao ensino de PLE. Por outro lado, o fato de que esses materiais são mais novos também faz com que seja mais provável que ainda sejam adotados em cursos e universidades que oferecem aulas de PLE.

Ao longo da próxima subseção, vamos comparar como cada um desses manuais apresenta alguns tópicos relevantes para o ensino de PLE. Os temas que selecionamos para esta pesquisa são: pronomes oblíquos, pronomes demonstrativos, pronomes pessoais retos, pronúncia do verbo estar, redução e contração da preposição para. Esses tópicos foram selecionados porque, como existe uma grande diferença entre a norma padrão e a forma como esses pontos gramaticais são, efetivamente, usados na língua falada, seria interessante comparar se os livros didáticos fariam uma ponte entre essas duas modalidades de língua. Em cada uma dessas análises, observar-se-ão as diferenças entre o que esses livros propõem e a forma como a língua é usada em situações não monitoradas de comunicação. Questiona-se, finalmente, que língua estamos ensinando aos alunos e, além disso, apresentam-se alguns aspectos da fala que poderiam ser contemplados no ensino de PLE para que os alunos possam adquirir uma modalidade de língua mais compatível com aquela que os brasileiros falam em situações espontâneas de comunicação.

\section{A língua falada nos livros didáticos de PLE}

Em nossa pesquisa, consideramos a dicotomia entre fala e escrita de uma forma dinâmica, e não como categorias estanques. Conforme Marcuschi (2001, p. 40-41) afirma, essas duas modalidades estão em extremos de um continuum em que há diversos gêneros textuais mais ou menos prototípicos

\footnotetext{
1 A única exceção para esse caso foi o livro de Simões (2008). Esse manual, apesar de ter sido publicado há mais de 10 anos, é exclusivamente para falantes de espanhol, por isso pareceu-nos interessante mantê-lo na análise, a título de comparação com livros que não são para esse público.
} 
de cada uma dessas categorias. Nesse sentido, um artigo científico seria o protótipo de língua escrita mais formal, ao passo que uma conversa espontânea seria o protótipo da fala mais informal. Entre esses dois extremos, residem outros gêneros textuais que transitam entre o mais formal e informal, como, por exemplo, notícias de jornal, receitas culinárias, noticiário de rádio ou televisão, textos narrativos, etc. Nesta pesquisa, usamos, por vezes, os termos "discurso mais monitorado" e "discurso menos monitorado" para nos referirmos a gêneros textuais mais típicos da escrita e da fala, respectivamente. Ao ensinar uma língua estrangeira, é importante nos questionarmos sobre que modalidade de língua estamos apresentando aos nossos alunos. Quando estiverem falando português, quais são os gêneros a que os alunos vão estar expostos com mais frequência e que, portanto, devem ser mais enfatizados na sala de aula? Essa deve ser uma pergunta a nortear nossa opção por uma modalidade mais próxima da língua falada ou escrita.

Castilho (1998, p. 11), ao analisar diferentes teorias de língua, afirma que

a terceira teoria considera a língua como uma atividade social, por meio da qual veiculamos as informações, externamos nossos sentimentos e agimos sobre o outro. Assim, (sic)concebida, a língua é um conjunto de usos concretos, historicamente situados, que envolvem sempre um locutor e um interlocutor, localizados num espaço particular, interagindo a propósito de um tópico conversacional previamente ancorado.

Desse modo, a língua não é um construto monolítico que os alunos devem apreender. Ela é sempre modulada pelos fatores mencionados anteriormente. Um letramento pleno em segunda língua não é possível se ensinamos uma versão abstrata de língua, despida do contexto interacional em que toda situação é engendrada, sobretudo no contexto de língua estrangeira, em que muitas vezes os alunos não estão familiarizados com os códigos culturais daquele país que fala a língua que estão aprendendo. É crucial que os atos linguísticos sejam ancorados em situações reais de uso em que as variantes linguísticas utilizadas sejam moldadas de acordo com os elementos supracitados.

Perini (1999, p. 24-25), após afirmar que a variedade de língua utilizada depende, sempre, da interação social e linguística em que nos encontramos, afirma o seguinte sobre as variantes coloquiais da fala e o padrão da escrita: "O que se pode concluir daí é que cada variedade tem seus domínios 
próprios, onde é senhora quase absoluta. Cada situação de comunicação [...] impõe uma variedade própria, que é 'certa' naquela situação.” Muitas vezes, no entanto, o que se observa é que os livros didáticos de PLE são baseados na gramática normativa e prescindem das informações socioculturais presentes nas interações. Perini (1999, p. 33-34) tece as seguintes considerações sobre a gramática normativa:

Defendo a ideia de que o ensino normativo não é um mal em si, mas que tem sido aplicado [...] de maneira prejudicial aos alunos. [...] Não quero dizer com isso que o ensino normativo deva ser suprimido. É preciso, apenas, colocá-lo em termos mais realistas. Não se trata de confrontar um "português certo" e um "português errado", definidos ambos em termos absolutos, independentemente do contexto situacional ou social. Trata-se, antes, de defender a ideia de que a cada situação corresponde uma variedade distinta da língua [...]

Sendo assim, a norma padrão é importante e tem seu lugar no ensino de PLE. Ela deve, no entanto, ser ancorada nos contextos próprios em que é prototípica, ou seja, textos escritos formais, sobretudo acadêmicos. Em outros domínios, modalidades de língua falada podem ser adotadas porque são mais compatíveis com o uso da língua nessas situações mais espontâneas. A fim de observar que modalidade de língua os livros didáticos de PLE adotam, vamos realizar uma análise abordando cada um dos tópicos gramaticais mencionados anteriormente. Antes disso, no entanto, vamos apresentar uma visão geral dos livros didáticos selecionados para este artigo. Listamos abaixo os referidos materiais, por ordem cronológica: 
Quadro 1 - Livros didáticos de PLE selecionados para comparação

\begin{tabular}{|c|c|c|c|c|}
\hline & Nome do livro & Autor/es & $\begin{array}{c}\text { Ano de } \\
\text { publicação }\end{array}$ & $\begin{array}{c}\text { Nível a que se } \\
\text { destina }\end{array}$ \\
\hline 1. & $\begin{array}{l}\text { "Pois não: Brazilian } \\
\text { Portuguese course for } \\
\text { Spanish speakers, with } \\
\text { basic reference grammar" }\end{array}$ & $\begin{array}{l}\text { Antônio R. M. } \\
\text { Simões }\end{array}$ & 2008 & $\begin{array}{l}\text { Elementar, interme- } \\
\text { diário e avançado }\end{array}$ \\
\hline 2. & $\begin{array}{l}\text { "Bom dia, Brasil! } \\
\text { Português básico para } \\
\text { estrangeiros" }\end{array}$ & $\begin{array}{l}\text { Rejane de } \\
\text { Oliveira Slade }\end{array}$ & 2012 & Elementar \\
\hline 3. & $\begin{array}{l}\text { "Ponto de encontro: } \\
\text { Portuguese as a world } \\
\text { language" }\end{array}$ & $\begin{array}{l}\text { Clemence M. } \\
\text { C. Jouët-Pastré } \\
\text { et al. }\end{array}$ & 2013 & $\begin{array}{l}\text { Elementar, interme- } \\
\text { diário e avançado }\end{array}$ \\
\hline 4. & $\begin{array}{l}\text { "Como está o seu } \\
\text { português?" }\end{array}$ & Otuki de Ponce & 2014 & Intermediário \\
\hline 5. & "Fale português volume 1" & $\begin{array}{l}\text { Harumi de } \\
\text { Ponce et al. }\end{array}$ & 2017 & Elementar \\
\hline
\end{tabular}

Fonte: elaborado pela autora.

A partir dos livros listados acima e também dos tópicos gramaticais mencionados anteriormente, começaremos nossa análise pelos pronomes de objeto direto. Vamos extrair tanto partes teóricas quanto exercícios ilustrativos de cada um dos livros selecionados.

Jouët-Pastré et al. (2013, p. 248) listam os seguintes pronomes de objeto direto: me, te, $o, a$, nos, vos, os, as. Como a variedade continental também é contemplada nesse livro, é provável que o pronome vos seja aplicado a essa modalidade, já que no Brasil ele não é usado nem mesmo na língua escrita em nível mais formal. Ao mencionar que, com verbos no infinitivo, elimina-se o - $r$ e acrescentam-se os pronomes -lo, -la, -los, -las, o livro apresenta os seguintes exemplos:

Você quer experimentar o casaco? Sim, quero experimentá-lo. A senhora vai ler os jornais? Sim, vou lê-los.

A Mafalda gosta de ouvir esta canção? Ela gosta de ouvi-la, sim. (JOUËT-PASTRÉ et al., 2013, p. 249, grifos da autora)

Claro que, na variedade formal (sobretudo escrita) da língua portuguesa, os pronomes oblíquos apresentados neste livro ainda persistem e é importante que sejam ensinados aos alunos porque pode ser que eles 
ocupem trabalhos nos quais tenham que escrever formalmente. Não há dúvida de que essa parte deva ser preservada no ensino. O que se questiona aqui, no entanto, é o contexto no qual se inserem os modelos apresentados no livro. Cada exemplo dado serve para uma conjugação verbal, a fim de que os alunos vejam os diferentes acentos gráficos na primeira e segunda conjugações e sua ausência na terceira. Os exemplos apresentados retratam situações de diálogo informal entre dois indivíduos. No primeiro caso, imaginam-se duas pessoas em uma loja, escolhendo roupas, e uma pergunta à outra se esta quer experimentar um casaco. No contexto do português do Brasil, nessa situação informal falada, o pronome oblíquo como apresentado no livro já não se usa. O mais natural seria a omissão pronominal, já que o referente está claramente explicitado pela frase anterior. Depois dos exemplos, o livro acrescenta essa informação:

Especially in Brazilian Portuguese, direct object pronouns $o$, $a$, os, and as are often omitted in coloquial speech: Você conhece este professor? Não, não conheço. A senhora vai experimentar a saia? Vou experimentar, sim. (JOUËT-PASTRÉ et al., 2013, p. 249, grifos da autora)

Essa explicação certamente é fundamental, mas está diretamente em conflito com o que foi mostrado nos exemplos anteriores. Seria mais interessante se o livro apresentasse um continum entre discurso monitorado e discurso não monitorado e mostrasse as duas possibilidades (presença dos pronomes oblíquos formais e ausência destes em discurso informal), mas fornecendo exemplos de pronomes formais compatíveis com a única realidade em que de fato aparecem, que é a de discurso mais monitorado. Uma atitude assim ajudaria mais aos alunos no sentido de lhes oferecer amostras significativas de língua de acordo com a realidade dinâmica que experienciamos no português do Brasil.

O mesmo livro (JOUËT-PASTRÉ et al., 2013, p. 249-250) posteriormente apresenta quatro exercícios de prática desses pronomes. $\mathrm{O}$ segundo desses exercícios tem o seguinte enunciado: "Uma negociação. Você e o seu(sua) novo(a) companheiro(a) de casa dividem as responsabilidades domésticas. Devem chegar a um acordo sobre o que cada um vai fazer". (JOUËT-PASTRÉ et al., 2013, p. 250) Como essas são instruções para uma conversa entre dois colegas sobre as tarefas que desempenham na casa, poderse-ia esperar o uso de pronomes de maneira informal, de acordo com uma 
conversa natural entre essas pessoas. No entanto, o exemplo apresentado como modelo é o seguinte: "E1: Você quer arrumar a cozinha? E2: Não, eu não quero arrumá-la. E1: Então eu vou arrumá-la”. A seguir, apresentam-se as tarefas domésticas que esses alunos devem compartilhar: arrumar as revistas, organizar os armários, varrer o terraço, etc. (JOUËT-PASTRÉ et al., 2013, p. 250) Em todos esses casos, a expectativa de resposta correta é "arrumá-las, organizá-los, varrê-lo”, e assim sucessivamente. Esses usos pronominais são corretos, mas não de acordo com o contexto que se apresenta no livro, que é uma conversa informal. Ensinar os pronomes dessa forma priva o aluno das multifaces do uso dessas palavras de acordo com a situação de comunicação.

Outro aspecto do tratamento dos pronomes oblíquos neste e em outros livros didáticos é o fato de eles não mencionarem o uso dos pronomes retos em vez dos oblíquos para substituir você, ele, ela, eles, elas, em casos como:

\section{- Você tem visto o Rodrigo?}

— Não, tem muito tempo que não vejo ele. Vi ele pela última vez quando vi você no dia do jogo.

Fazendo uma busca ilustrativa pela forma vi ele no Corpus do português, ${ }^{2}$ observamos que essa construção começou a ser usada na nossa língua no século XIX, no discurso literário, em uma situação de diálogo. Cinco ocorrências foram registradas nesse século, das quais extraímos as seguintes:

"Mas, juro que não vi ele saltar o muro"

"Ahn! eu não disse que Sinhá viu coisa? Eu também vi ele". (DAVIES; FERREIRA, [2008], grifos da autora)

Esses excertos de corpora do português brasileiro (PB) mostram que o uso do pronome oblíquo idêntico ao reto já existe há bastante tempo na língua. O fato de que os autores usam essa construção quando querem espelhar diálogos informais nos informa sobre a consciência de que essas são formas da oralidade, no continuum mais extremo do discurso não monitorado. No português de Portugal, essa forma também foi registrada no mesmo corpus e na mesma situação, mas em quantidade mais reduzida (apenas uma ocorrência).

\footnotetext{
2 Esse corpus apresenta cerca de 45 milhões de palavras desde o século XIV até o XX, incluindo dados do português europeu e do brasileiro, extraídos de registros orais, de ficção, jornalístico e acadêmico. Nesse corpus, é possível fazer buscas não só por palavras exatas, mas também por frases ou classes gramaticais, bem como por palavras adjacentes.
} 
Alguns livros didáticos, como Slade (2012, p. 160) fazem menção ao uso dos pronomes de acordo com o português falado informalmente: "O português falado no Brasil apresenta duas tendências. A primeira é usar o mesmo pronome para as duas funções, sujeito e objeto. A segunda é omitir totalmente o pronome." Não obstante, o exercício proposto, simulando diálogos, apresenta-se da seguinte forma:

A. Complete as frases com os pronomes o(s) / a(s):

1. Paulo, você encontrou o Carlos?

Sim, eu encontrei na semana passada.

2. Você comprou os livros de português?

Sim, eu comprei na livraria perto de meu escritório. (SLADE, 2012, p. 161)

O fato de este livro ter mencionado os usos mais informais dos pronomes oblíquos já é um grande passo, mas seria interessante, também, se os exercícios fossem compatíveis com essa abordagem. Como se trata de diálogos, os alunos poderiam usar a forma de pronome pessoal reto, em vez do oblíquo: "Sim, eu vi ele na semana passada". Esses dois casos refletem melhor a realidade linguística de uso desses pronomes no discurso menos monitorado, seja ele falado ou até mesmo escrito, em casos de mensagens de texto e gêneros informais desse tipo.

Os pronomes de objeto também são amplamente estudados na linguística descritiva, o que nos fornece uma base para os questionamentos que fazemos acerca do uso dessa classe de palavras no discurso mais informal. Perini (2010, p. 120, grifos da autora) afirma que

Alguns pronomes só têm uma forma, que vale para todas as funções. É o caso de ele, ela e seus plurais, que não variam formalmente quando em posições diferentes:

[...] Eu chamei ele para ajudar na cozinha.

[...] De repente eu vi eles chegando de táxi.

Castilho (2010, p. 479) afirma que "o acusativo $o$ tem os alomorfes lo e no, e está desaparecendo, [...] sendo substituído pela forma única ele acusativo". Assim, as gramáticas descritivas do português já assumem que as formas tradicionais de pronome oblíquo $(o, a, o s, a s)$ estão em desuso no PB. Sendo assim, estudos mais focados na linguística descritiva e na pluralidade 
da gramática já observam que esses usos pronominais de acordo com a norma padrão não correspondem mais à realidade do PB.

O que se está tentando propor aqui não é que os livros didáticos ignorem a gramática normativa da língua portuguesa. Esta tem seu lugar e deve ser ensinada, mas no contexto situacional adequado. O uso de $o, a$, os, as para pronomes de terceira pessoa - de acordo com o que é prescrito pela norma padrão - é válido para textos escritos altamente monitorados, mas não se aplica a conversas no discurso menos monitorado, por isso não deve ser usado em exemplos que apresentem conversas do cotidiano. Além disso, como a maioria dos alunos que estudam português geralmente tem como objetivo viajar para o Brasil e se comunicar com falantes nativos, seria interessante que os livros didáticos mencionassem possibilidades de uso desses pronomes mais coerentes com a língua falada. É importante que o aluno seja informado sobre formas variantes do mesmo traço gramatical. Só assim ele poderá adequar sua fala à situação de comunicação em que se encontrar. Poder-se-ia argumentar que, em cursos elementares, não seria benéfico fornecer ao aluno tantas informações sobre essas peculiaridades da língua. Na realidade, o que observamos, com base em anos de experiência no ensino de PLE, é que a aprendizagem da modalidade não monitorada deve prevalecer sobre a gramática normativa porque aquela será de mais utilidade do que esta. Além disso, o foco no ensino da norma padrão faz com que o aluno cristalize formas linguísticas não compatíveis com o discurso menos monitorado, o que pode ser mais difícil de relativizar posteriormente.

Passemos, agora, à análise do que os livros didáticos apresentam em termos de pronomes demonstrativos. Harumi de Ponce (2017, p. 9), Slade (2012, p. 30) e Jouët-Pastré et al. (2013, p. 205) apresentam as formas este (para objetos próximos de quem fala, no espaço "aqui"), esse (para objetos próximos da pessoa com quem se fala, no espaço "aí") e aquele (para objetos longe dos interlocutores, no espaço "ali" ou "lá"). Todas essas formas são acompanhadas de suas flexões de gênero e número (esta, isto, aquilo, etc.). Slade (2012, p. 31) apresenta os seguintes exemplos de uso desses pronomes:

"O que é isso? Isto é meu novo notebook.

De quem é esse copo? Este copo é meu."

Otuki de Ponce (2014, p. 49) apresenta a seguinte atividade para praticar esses pronomes: 
Exercício 1 - Em uma loja - Complete com este, esse, aquele.

A: Posso ver............... relógio aí, perto de você?

B:

A: Quanto é? aqui? Claro!

B: R $\$ 150,00$.

A: É muito caro. E............... aqui?

B:.............. aí é mais barato. $\mathrm{R} \$ 120,00$.

Jouët-Pastré et al. (2013, p. 208) propõe um exercício em que duas pessoas estão em um apartamento e "vão decidir onde colocar vários móveis e acessórios". As perguntas sugeridas para ajudar nesse diálogo são: "E1: As colchas ficam neste armário ou nesse? E2: Acho que nesse. E a poltrona grande? E1: A poltrona grande fica neste quarto." (JOUËT-PASTRE et al., 2013, grifos da autora).

O traço que chama a atenção em todas essas abordagens é o uso de este (e suas variações) em exemplos que simulam situações coloquiais de diálogo falado. Para investigar melhor o status desse pronome na língua oral, fizemos uma busca no Corpus do português pelas ocorrências do pronome este nos diversos contextos que esse banco de dados apresenta. Os resultados estão expostos na tabela a seguir:

Tabela 1 - Frequência de ocorrência do pronome este no Corpus do português

\begin{tabular}{l|c|c}
\hline \multicolumn{1}{c|}{ Tipo de texto } & Ocorrências & Porcentagem \\
\hline Notícias & 7.531 & $38,3 \%$ \\
Registro acadêmico & 6.816 & $34.7 \%$ \\
Ficção & 3.592 & $18,3 \%$ \\
Discurso oral & 1.706 & $8,7 \%$ \\
Total & $\mathbf{1 9 . 6 4 5}$ & $\mathbf{1 0 0 \%}$ \\
\hline
\end{tabular}

Fonte: elaborado pela autora.

Conforme a tabela acima mostra, dos 19.645 casos de este registrados no Corpus do português, a porcentagem que aparece no discurso oral é a menor, $8,7 \%$. Esse pronome é majoritariamente usado nas notícias e no registro acadêmico. O mesmo corpus também mostra que, a partir do século XVII, esse pronome está sendo progressivamente menos usado, tanto no 
português do Brasil quanto no de Portugal. Sendo assim, questiona-se por que os livros didáticos devem ensinar uma variedade que não é tão frequente na língua falada. Obviamente que é importante que o aluno aprenda o pronome este e suas variantes. Pode ser que em algum momento o aluno tenha que escrever textos acadêmicos em que esse uso seja importante; no entanto, como em cursos de elementar I o principal uso da língua é para a conversação (em sala de aula ou fora dela), não parece adequado que esse pronome predominantemente da escrita seja aprendido como a única norma para a fala. Nenhum dos livros consultados menciona o fato de que o pronome este é o correto pela norma padrão, mas, na fala cotidiana, já usamos esse para os espaços de "aqui" e "aí", situações em que a gramática normativa usaria este e esse, respectivamente.

Castilho (2010, p. 498) aponta que, no PB, existe um “esquema binário generalizado, com uma disputa entre este/esse, e uma estabilidade em aquele." É interessante, então, observar essa aparente contradição entre o que ensinam os livros didáticos sobre os pronomes demonstrativos e o uso real que se faz dessa classe de palavras na língua falada. Conforme afirmado anteriormente, é importante ensinar esses pronomes dentro do contexto de uso mais frequente, ou seja, na língua escrita formal. Os livros, no entanto, os apresentam dentro de contextos de diálogos, o que dá aos alunos a falsa impressão de que é nessa situação de comunicação que esses pronomes devem ser usados. Seria necessário fazer uma adaptação ou dos exemplos - transformando-os em excertos de língua formal -, ou das explicações teóricas, acrescentando que o pronome este e suas variações existem, mas somente no discurso formal escrito. Na língua falada, esse funciona como esse ou este, em oposição a aquele, conforme Castilho (2010) postula.

Vamos analisar, agora, outro aspecto interessante para observar a questão da variação linguística: a tabela de pronomes pessoais retos que cada livro didático apresenta. Esse tópico geralmente é abordado no começo dos livros, quando os paradigmas de conjugação verbal são apresentados. Fazendo um apanhado dos conteúdos nos livros selecionados, observamos os seguintes paradigmas de pronomes pessoais retos: 
1. Simões (2008, p. 39): eu, você, ele/ela, nós, vocês, eles/elas

2. Slade (2012, p. 35): eu, você, o senhor/a senhora, ele/ela, nós, vocês, os senhores/as senhoras, eles/elas

3. Jouët-Pastré et al. (2013, p. 39): eu, tu, você/o senhor/a senhora, ele/ela, nós, vocês/os senhores/as senhoras, eles/elas

4. Otuki de Ponce (2014, p. 79): eu, tu, você, ele/ela, nós, vocês, eles/elas

5. Harumi de Ponce (2017, p. 9): eu, você, ele/ela, a gente/nós, vocês, eles/ elas/as pessoas

A inclusão de ela em todas essas tabelas é um passo importante em relação à igualdade de gênero, um tema que também é muito recorrente em análises sobre como os materiais didáticos lidam com a diversidade inerente à sociedade. É interessante notar que nenhum dos livros apresenta a forma vós, já em desuso no PB. Esse pronome ainda aparece em gramáticas normativas do PB, mas, provavelmente por ser arcaico na língua, já foi eliminada dos livros didáticos. Outro aspecto que chama a atenção é que os livros 2 e 3 acrescentam as formas o senhor, a senhora, os senhores, as senhoras. Esses pronomes de tratamento usados, geralmente, para pessoas de mais idade ou hierarquicamente superiores ao locutor não constam nas tabelas de pronomes pessoais retos em gramáticas tradicionais do português. A presença dessas formas não seria, obrigatoriamente, necessária em uma tabela assim, mas talvez possa ajudar os alunos a memorizarem as ocorrências e o uso dessas formas importantes na cultura brasileira. O livro 5 difere dos outros materiais por apresentar a forma as pessoas como pronome de terceira pessoa do plural. Essa parece ser uma adição desnecessária, visto que esse não é um pronome de tratamento (como o senhor e suas variações) e, no $\mathrm{PB}$, existem outras formas coletivas de se referir a um grupo de pessoas (povo, pessoal, galera, etc.). Elencar todas essas possibilidades seria exaustivo e não produtivo em uma tabela de pronomes pessoais cujo objetivo é ensinar os alunos a tratarem corretamente as pessoas em português, bem como a conjugar verbos de acordo com o paradigma para cada forma. Os livros 3 e 4 ainda conservam a forma $t u$, o que é um ponto positivo porque contempla a forma dialetal usada em algumas regiões do Brasil, bem como no português europeu e africano, mas, por outro lado, nos dois livros em que essa forma foi mantida, não se menciona que alguns estudos do PB apontam para o fato de que $t u$ parece estar ressurgindo na língua, mas adotando a conjugação de 
terceira pessoa (tu vai em vez de tu vais). Duarte (2018, p. 86), por exemplo, observa "o retorno de $t u$ às peças [de teatro] aqui analisadas, no último quartel do século XX, [que] já apresenta a forma verbal sem a desinência marcada, estando em perfeita variação com você’.

Finalmente, resta comentar que o livro 5, talvez por ser o mais novo, é o único que apresenta a forma a gente em sua tabela de pronomes. Apesar disso, nesse livro, nenhuma explicação é apresentada para o fato de que a gente é usado em situações mais informais e compete com nós. Também não se comenta o fato de que a gente é equivalente a nós, no sentido de que a pessoa que usa esse pronome está incluída no grupo a que se refere. Outro ponto que passa despercebido é o fato de que, na língua falada informalmente, $a$ gente é mais usado do que nós. Nos livros que não apresentam a forma a gente, alguns dos exercícios são de língua falada e apresentam exclusivamente a forma nós, como se essa fosse a preferência dos brasileiros quando estão em conversas informais. Castilho (2010, p. 478) postula que " $\mathrm{Na}$ primeira pessoa do plural, nós tem sido substituído pelo sintagma nominal indefinido a gente...". Duarte (2018, p. 86), analisando textos de 1930, afirma que "Já se anuncia também uma forte competição entre os pronomes nós e a gente, uma competição que vai se resolver em favor de a gente a partir dos anos 1970 [...], quando passamos a ter, para referência à primeira pessoa do plural, o predomínio de a gente e um uso muito parcimonioso de nós".

Novamente enfatiza-se, aqui, a incoerência entre o tipo de texto e a forma linguística usada. Se o que se está tentando ensinar são conversas informais em português, seria importante mencionar o pronome a gente, devido à sua grande prevalência na língua falada. Claro que não se deve inundar o aluno com informações desnecessárias que lhe compliquem a tarefa de aprender a língua. Mesmo assim, a exposição a certas formas tão prevalentes na oralidade deve ser importante para alunos que vão, primariamente, falar a língua. Ao assistirem a um filme ou conversarem com alguém em português, esses alunos fatalmente vão notar a existência da forma a gente. Por outro lado, ao falarem um português em que essa forma não existe, usarão uma modalidade linguística incompatível com o estilo que falantes nativos adotam. Seria importante, portanto, acrescentar a forma a gente à tabela de pronomes pessoais retos ou, pelo menos, comentar, no capítulo sobre pronomes, que essa forma existe e é mais usada do que nós na língua falada.

Outro aspecto que os livros didáticos geralmente não mencionam é relacionado à pronúncia da fala natural em situações não monitoradas, ou até 
em situações que simulam essa modalidade, como em posts ou mensagens enviadas em mídia social. Nesse aspecto, vamos mencionar dois exemplos, um sobre a pronúncia do verbo estar e outro sobre a redução da preposição para seguida da sua contração com artigos, sobretudo definidos.

No português brasileiro, em situações menos monitoradas de comunicação, o verbo estar, em todos os tempos, modos e pessoas pronominais, está em um amplo processo de apagamento da sua primeira sílaba, es. Consultando-se o Corpus do português, no discurso oral, encontramos diversos exemplos dessa redução:
"mas a gente tava conversando sobre o quê?" (estava)
"o ar condicionado tá desligado, tá quebrado e não tem reparo." (estar)
"cozinhe a galinha e quando tiver assim já: refolgada (sic)..." (estiver). (DAVIES; FERREIRA, [2008], grifos da autora)

Após consultarmos os livros didáticos de Simões (2008), Slade (2012), Jouët-Pastré et al. (2013), observamos que todos eles apresentam a conjugação de estar, bem como as diferenças básicas entre ser e estar, mas nenhum deles menciona a redução do verbo estar no discurso menos monitorado. Os exercícios apresentados são configurados em situações informais de comunicação, em que falantes nativos provavelmente usariam a redução. Abaixo citamos dois exemplos desses exercícios:

Slade (2012, p. 43) propõe o seguinte exercício:

B. Responda às perguntas usando frases completas:

1. Onde estão os estudantes?

2. Quem está no Vaticano?

3. Onde está o dinheiro?

Jouët-Pastré et al. (2013, p. 49) elaboram uma atividade em que um aluno deverá perguntar ao outro sobre a localização de diversos objetos na sala de aula. O exemplo de interação que se dá como modelo é o seguinte: "E1: Onde está o livro do/da professor/a? E2: Está na mesa." Nos dois livros analisados, nesse contexto de pergunta e resposta em uma conversa, o uso prevalente seria de tá e não está. Ao comentarem o presente progressivo, formado com verbo estar + gerúndio (estou trabalhando, etc.) ou as expressões com estar (estou com fome) esses livros também não mencionam essa redução na pronúncia. Talvez pareça que o aprendiz de 
PLE em nível elementar ficaria sobrecarregado com essas informações tão detalhadas sobre pronúncia. Na verdade, quando os alunos aprendem dessa forma autêntica, compatível com o que se fala no Brasil, sua capacidade de compreensão auditiva é muito melhor, porque essa é a língua usada naturalmente em vídeos e músicas. Além disso, quando alcançam níveis mais avançados, os alunos já sabem essas estratégias de redução de palavras e, por isso, conseguem se comunicar de forma mais eficiente. Um terceiro ponto a mencionar aqui é que, uma vez que o aluno cristaliza certas pronúncias ensinadas em nível elementar, é mais difícil mudar isso em cursos mais avançados. Sendo assim, ao ensinar o verbo estar, uma breve menção à sua pronúncia certamente vai facilitar bastante o desenvolvimento dos alunos em termos de compreensão e proficiência, principalmente porque esse é um verbo muito frequente no português e sua pronúncia mais natural fará com que os alunos falem de um jeito mais próximo à forma nativa.

Perini (2010, p. 352), em uma subseção específica dedicada à pronúncia do verbo estar, afirma que "No verbo estar, um dos mais frequentes da língua, a primeira sílaba é normalmente omitida, em todas as formas do verbo. [...] As formas plenas, estou, estava, etc., também ocorrem, mas são muito mais raras, e parecem ser especializadas para contextos enfáticos [...]. Mas mesmo nesse contexto tava seria adequado". Existem, portanto, estudos linguísticos que amparam esse uso informal e já disseminado do verbo estar.

O segundo ponto mencionado aqui em relação à pronúncia e à redução de palavras é sobre a preposição para. A maioria dos livros apresenta a diferença entre para e por, o que é um objeto de bastante confusão para os alunos. Simões (2008, p. 208) comenta as principais diferenças entre essas preposições e também cita a combinação de para com pronomes pessoais em expressões como em para mim, para você, etc. Jouët-Pastré et al. (2013) também mostram a diferença entre por e para e apresentam o seguinte exercício:

6-21 Para quem são os presentes? Você foi de férias a Lisboa e comprou muitos presentes para levar para casa. Um/a colega quer saber para quem são os presentes.

Modelo o CD dos Madredeus

E1: Para quem é o CD dos Madredeus?

E2: É para o meu irmão.

1. a pulseira 2. os brincos 3. o dicionário português/inglês 4 . o azulejo 5. a gravata 6. A carteira. (JOUËT-PASTRE et al. 2013, p. 254) 
Em contextos de discurso não monitorado como os apresentados no exercício acima e em outros, a preposição para é frequentemente reduzida a pra. Além disso, quando seguida de artigo definido ou indefinido, essa preposição e a palavra subsequente sofrem contração: pro, pra, pros, pras, prum, pruma, pruns, prumas. Em certos dialetos, como o mineiro, acontecem outras contrações, como pr'ce ou procê. Perini (2010, p. 357) menciona que "Todas as contrações com para são exclusivas da língua falada; e a preposição, como sabemos, é sempre pronunciada pra". Posteriormente, o mesmo autor (PERINI, 2010, p. 357-358), além dessas formas de contração com para e artigos, também menciona a ocorrência destas outras formas de contração: praquele (para + aquele), prele $($ para + ele), procê $($ para + você $)$,praqui $($ para + aqui), prali (para + ali), praí (para+ ai), proutro (para + outro).

Huback (2012), fazendo uma pesquisa sobre a redução e contração de para, de acordo com dados do Corpus do português, observa que a alternância entre para e pra começou no século XV. A redução de para a pra precedeu as demais contrações. Pro (para $+o)$, pros (para + os) e pras (para + as) surgiram no século XIX. Já prum (para um) e pruma (para uma) surgiram somente no século XX. Suas respectivas formas de plural não foram registradas. Esse mesmo estudo também observa que a frequência da sequência para + palavra subsequente é o que mais interfere na contração. Sendo assim, para é mais reduzido a pra em expressões como para mim, para você, para frente, para casa, para cima, dentre outras. Esse estudo demonstra que, na língua falada, essas reduções e contrações já chegam até a ultrapassar as ocorrências de preposição na sua forma para + palavra subsequente. Seria interessante, portanto, que os livros de PLE contemplassem também esse aspecto da língua menos monitorada ou, alternativamente, elaborassem exercícios baseados mais especificamente na língua monitorada, o que incorreria no uso de para.

Na próxima subseção, apresentamos sugestões de itens que podem ser incorporados ao ensino de PLE para que possamos apresentar aos alunos uma modalidade de língua mais compatível com o discurso não monitorado.

\section{Por uma metodologia de língua falada no ensino de PLE}

Os casos apresentados na subseção anterior são apenas exemplos das discrepâncias que existem entre o ensino de PLE e a língua que se fala no Brasil em situações não monitoradas de comunicação. Em geral, os materiais de PLE analisados neste artigo partem do pressuposto de que a 
gramática tem uma forma única (a normativa) que deve ser ensinada aos alunos independentemente da situação de comunicação em que os falantes se encontram. Nesse sentido, pode-se, também, questionar a inadequação do que os livros didáticos ensinam (norma padrão) e dos exercícios que são propostos, que são baseados em diálogos que não seguem o padrão normati em situações reais de comunicação. Defende-se que é necessário incorporar elementos da língua falada ao ensino de PLE, ou seja, adotar uma modalidade de língua que, de fato, reflita aquilo que os brasileiros falam. A gramática normativa pode ser mantida, mas dentro do seu contexto de uso específico. Sendo assim, com vistas a incorporar temas do discurso não monitorado ao ensino de PLE, sugerimos a adoção ilustrativa (não exaustiva) dos seguintes tópicos:

- Apagamento do R final em verbos no infinitivo: Vou almoça agora.

- Apagamento do R final em nominais (adjetivos, advérbios, preposições e substantivos): melhof, apesar, computador

- Redução e contrações da preposição para: pra, pras, pro, pros, pruns, prumas, etc.

- Uso de a gente como pronome pessoal reto

- Uso das formas de pronome pessoal reto no contexto de pronomes oblíquos: en vi ele, etc.

- Fusão dos usos de este e esse (e variantes) no uso único de esse (e variantes)

- Apagamento de es- no verbo estar em todos os modos e tempos verbais: ele está bem.

- Reduplicação do pronome que: Que que você tá fažendo aí? Que que ele queria?

- Redução de vocêa cêe em certos contextos sintáticos: Eocê vai vir aqui hoje à noite?

- Uso do imperfeito no lugar do condicional: Se eu fosse você, ia mais cedo hoje (em vez de iria)

- Uso do verbo ter em vez de haver ou fazer para indicar tempo passado: tem cinco anos que a gente não se vê (em vez de há/faz cinco anos...)

Alguns detalhes de pronúncia também poderiam ser mencionados, tais como:

- Redução de $e$ e $o$ átonos em fim de palavra: telefoni, bolu (telefone, bolo)

- Pronúncia do $r$ de acordo com o contexto dentro da palavra: início de palavra, fim de sílaba ou de palavra, intervocálico, em encontros consonantais, RR 
- Pronúncia do $m$ e $n$ nasalando a vogal anterior em fim de sílaba ou palavra: antes, cantam, bebem, ontem, etc.

- Pronúncia de $t$ e $d$ palatalizados diante de $i$ ou em fim de palavra diante de $e$ átono: tímido, dia, noite, tarde

Outros elementos, sobretudo aqueles relacionados a interações discursivas, poderiam ser acrescidos a essa lista. Preferimos, no entanto, mantê-la mais reduzida para que seja factível de acordo com a realidade de cursos de PLE. Outro ponto relevante a acrescentar aqui é que o professor, muitas vezes, ao observar as limitações que o livro didático impõe, geralmente elabora exercícios para que o ensino desses e outros tópicos gramaticais seja mais compatível com o uso da língua em situações reais de comunicação. Não se pode, portanto, reduzir o ensino de PLE aos livros didáticos. O professor tem um papel crucial nessa dinâmica.

\section{Conclusões}

Nossa análise de tópicos gramaticais em livros didáticos recentes de PLE mostrou que a modalidade de língua preferida por esses materiais foi a norma padrão. Observamos, também, uma incoerência entre as explicações teóricas apresentadas nos livros e os exercícios propostos. Os temas são ensinados a partir da perspectiva da norma padrão, mas os exercícios simulam diálogos coloquiais, levando o aluno a aplicar a norma padrão em situações informais, dando-lhe a falsa impressão de que é assim que os brasileiros falam em situações naturais de comunicação. A norma padrão tem seu lugar no ensino de PLE, mas seria importante que fossem criadas situações de comunicação em que ela é realmente usada, ou seja, em contextos altamente formais de língua escrita. No caso de diálogos como os que os livros didáticos propõem, seria importante ensinar as variantes da língua falada, já que essas são, efetivamente, as que os brasileiros usam. Propõe-se, principalmente, que o ensino de PLE incorpore aspectos da língua falada e, também, da situação de comunicação em que os falantes se encontram. Não existe língua única. Cada interação é moldada dentro de um contexto social e comunicativo em que as pessoas se encontram. Ao considerar esse todo da comunicação, estaremos, de fato, promovendo um letramento mais amplo de nossos alunos de PLE. 


\section{Referências}

CASTILHO, A. A língua falada no ensino de português. São Paulo: Contexto, 1998.

CASTILHO, A. Nova gramática do português brasileiro. São Paulo: Contexto, 2010.

DAVIES, Marc; FERREIRA, Michael J. O corpus do português. 45,000,000 words / palavras. 1300s-1900s. Provo: Brigham Young University, [2008]. Disponível em: https://www.corpusdoportugues.org/hist-gen/2008/x.asp. Acesso em: 23 jun. 2021.

DE PONCE, M. Como está o seu português? São Paulo: HUB, 2014.

DE PONCE, M. et al. Fale português volume 1. São Paulo: HUB, 2016.

DUARTE, M. E. Do pronome nulo ao pronome pleno: a trajetória do sujeito no português do Brasil. In: ROBERTS, I.; KATO, M. A. Português brasileiro: uma viagem diacrônica. 3. ed. São Paulo: Contexto, 2018. p. 83-106.

HUBACK, A. P. Chunking and the reduction of the preposition para 'to, for' in Brazilian Portuguese. Studies in Hispanic and Lusophone Linguistics, Berlin, v. 5, n. 2, p. 277-29, 2012.

JOUËT-PASTRÉ et al. Ponto de encontro: Portuguese as a world language. Pearson: Upper Saddle River, 2013.

MARCUSCHI, L. A. Da fala para a escrita: atividades de retextualização. São Paulo: Cortez, 2001.

PERINI, M. Gramática descritiva do português. São Paulo: Ática, 1999.

PERINI, M. Gramática do português brasileiro. São Paulo: Parábola, 2010.

SLADE, R. Bom dia, Brasil! Português básico para estrangeiros. New Haven: Yale University Press, 2012.

SIMÕES, A. Pois não: Brazilian Portuguese course for Spanish speakers, with basic reference grammar. Austin: University of Texas Press, 2008.

Data de submissão: 14/07/ 2020. Data de aprovação: 23/03/2021. 